\title{
El doble y tres relatos de Julio Cortázar ${ }^{1}$
}

\section{(The Double and Three Short Stories by Julio Cortázar)}

\author{
Isabel Cristina Bolaños Villalobos ${ }^{2}$ \\ Universidad Nacional, Costa Rica \\ Gabriela Cerdas Ramírez ${ }^{3}$ \\ Universidad Nacional, Costa Rica \\ Jimmy Ramírez Acosta ${ }^{4}$ \\ Universidad Nacional, Costa Rica
}

\section{resumen}

Se analiza la noción del doble, según Sigmund Freud y el psicoanálisis, y su presencia en tres cuentos de Julio Cortázar. Su lectura se deriva de la perspectiva de lo ominoso, una de las posibles lecturas a Cortazár, dada su apertura y la complejidad del tema del doble. Pese de las múltiples variaciones que el doble cortazariano experimenta en diferentes cuentos, mantiene suesencia.

\begin{abstract}
This article addresses the notion of the Double, according to Sigmund Freud and psychoanalysis, and its relation to three Julio Cortazar's short stories. The texts are read from the perspective of the uncanny, as one of the possible approaches that can be applied to Cortazar's writings, due to the openness and complexity of the topic of the Double. In spite of the variety of the Cortazar's Double in the different stories, it retains an essence described here.
\end{abstract}

1 Recibido: 20 de febrero de 2013; aceptado: 19 de julio de 2013.

2 Escuela de Literatura y Ciencias del Lenguaje. Correo electrónico: ibolano@una.cr

3 Escuela de Literatura y Ciencias del Lenguaje. Correo electrónico: gcerdas@una.cr

4 Escuela de Literatura y Ciencias del Lenguaje. Correo electrónico: jiramire@una.cr

$$
L_{\text {etras }} 54 \text { (2013), ISSN 1409-424X; EISSN 2215-4094 }
$$


Palabras clave: doble, psicoanálisis en literatura, narrativa hispanoamericana Keywords: Double, psychoanalysis in literature, Spanish-American literature

Se analiza el tema del doble a partir de Freud y el psicoanálisis, para estudiar tres relatos de Julio Cortázar, contenidos en Bestiario $^{5}$ : «Casa tomada», «Carta a una señorita en París» y «Lejana». En numerosos estudios realizados sobre la noción del doble, se ha señalado que su manifestación se da principalmente desde tres perspectivas ${ }^{6}$ : 1. el diabólico (ominoso, aterrador); 2. el purificador (realización espiritual); o 3. ambos (dual, sacro-satánico).

Estas características no se presentan en su totalidad en una producción textual determinada y el presente parte de Freud y el psicoanálisis, lo que nos remite a su concepción psicoanalítica, derivada de Das Unheimlich (1919), o Lo siniestro, que orienta a convenciones estéticas de la literatura y del estudio de Néstor Braunstein en «Nada que sea más siniestro que el hombre» ${ }^{7}$.

La lectura de cada cuento, respectivamente, se deriva más de la primera perspectiva citada, lo ominoso. A la vez esta es sólo una posible lectura debido a que la apertura que presenta la obra de Cortázar se presta a múltiples interpretaciones, y más aún en cuanto a un tema tan complejo como el del doble.

La génesis del doble aparece por la búsqueda de la individualidad, del saber quién soy, del yo. Es una manifestación que se da tanto a nivel psicológico como discursivo, y en ella surge la representación de lo simbólico. El doble presenta un monólogo interior que se torna diálogo, debido a que el personaje se comunica consigo mismo conforme a sus anhelos y preocupaciones. El yo del personaje se duplica para ser reconocido por otro, para autoidentificarse en la medida en que ese otro yo lo reconozca.

5 Julio Cortázar, Bestiario (Buenos Aires: Editorial Sudamericana,1995).

6 Sigmund Freud, Lo siniestro (Buenos Aires: Amorrortu, 1979).

7 Néstor Braunstein, «Nada que sea más siniestro (unheimlich) que el hombre», A medio siglo de «El malestar en la cultura», $5^{\text {a }}$ ed. (México, D. F.: Siglo XXI, 1988) 191-228. 
No podemos pasar por alto, entonces, con base en Freud, la relación interna de imbricación y articulación que atraviesa el doble y lo siniestro, «lo siniestro sería aquella suerte de espantoso que afecta las cosas conocidas y familiares desde tiempo atrás ${ }^{8}$. Por esto, lo $\mathrm{Un}$ heimlich remite a lo Heimlich, por cuanto es «algo» familiar a la vida psíquica que ha devenido extraño mediante el proceso de represión.

Aspecto esencial es que la represión es casi un sinónimo de un «malestar en la cultura»; es en la cultura en donde el ser humano edifica su identidad, que no podría conferírsele a sí mismo y que a cambio tendrá que someterse a la ley. Esta ley exige la renuncia al objeto de su deseo, implanta la prohibición del incesto al instituir la renuncia a la madre, «primer objeto de deseo, tanto para el varón como para la mujer»". La cultura se basa en la insatisfacción de la sexualidad, por lo que la cultura es indisociable de la represión, «del imposible reaporte sexual»; como lo señala Braunstein, «la misma expresión malestar en la cultura equivale a un pleonasmo, puesto que si hubiese bienestar habría caos y no cultura $»^{10}$.

Pese a los diques (represiones) impuestos al deseo, hacedores del humano como ente cultural, el sujeto se ve obligado también a buscar incansablemente ese objeto a través de otro idéntico que alucina, fantasea, puesto que el original está perdido, irrecuperable. Por tanto, es innombrable, no se manifiesta tal cual es en el inconsciente, sino a través de deformaciones oníricas, intento del sueño por evitar loprohibido.

Volvamos a nuestro objeto de estudio: implícito en el tema del doble y por tanto de lo siniestro está el deseo y el deseo prohibido, de manera que: «Nada es más pavoroso, más siniestro que ver la imagen del propio deseo hecha realidad $»^{11}$. Freud destaca en «Lo ominoso ${ }^{12}$ dos tesis psicoanalíticas: 1 . Todo efecto de un impulso emocional es convertido por la represión en angustia, de manera

\footnotetext{
8 Freud, 2484.

9 Braunstein, 205.

10 Braunstein, 215.

11 Braunstein, 214.

12 Freud, 2493.
} 
que lo angustioso es algo reprimido que retorna; y 2. Lo siniestro no sería nada nuevo, sino más bien algo familiar a la vida psíquica y que se tornó extraño mediante el proceso de su represión. Lo angustioso se transforma en siniestro, ante el animismo, la magia y los encantamientos, la omnipotencia del pensamiento, las actitudes frente a la muerte, las repeticiones no intencionales y el complejo de castración. Sin embargo, una de las más conocidas formas de lograr el efecto de lo siniestro es mediante la provocación del doble, del otro yo con sus múltiples variaciones:

- la aparición de personas con fisonomías idénticas;

- la trasmisión de los procesos anímicos de una persona a su doble (telepatía);

- la identificación de una persona con otra perdiendo el dominio del yo, es decir, desdoblamiento del yo, partición del yo;

- el constante retorno a lo semejante: repetición de los mismos rasgos faciales, caracteres, destinos, actos criminales, aún de los mismos nombres en varias generaciones sucesivas ${ }^{13}$.

El tema del retorno es propio del doble y, por tanto, de lo siniestro. Es el retorno a ciertas fases de la evolución del sentimiento «yoico», el retorno involuntario a un mismo lugar y la repetición involuntaria hacen parecer siniestro lo que en otras circunstancias se habría pensado como casualidad. Dentro de este marco teórico podemos ligar fácilmente tres conceptos que hemos venido mencionando: doble - siniestro - deseo, a través de un enunciado de Schelling que se refiere a Dans Unheimlich, y que Freud retoma en su ensayo: «Se denomina Unheimlich todo lo que, debiendo permanecer oculto, secreto... no obstante se ha manifestado» ${ }^{14}$. 


\section{El doble, Cortázar y el surrealismo}

Evelyn Picón Garfield señala que para entender los textos de Cortázar hay que tener en cuenta la influencia surrealista ${ }^{15}$. Los sueños (realidad dual, sueño-vigilia), la revolución, la obsesión, la subversiva postura frente a la tradición, el juego, la niñez, la locura y por supuesto la monstruosidad, pariente cercano del doble, han sido profundizados por innumerables ensayistas y estudiosos del surrealismo, y rasgos característicos del movimiento con los cuales afrenta Picón en la obra de Cortázar.

Mientras tanto, Rachel Philips a propósito de Octavio Paz, indica que el tema del doble llegó a ser característico de los surrealistas, aunque indudablemente no podrían demandar exclusividad. Señala que la filosofía surrealista expresó frecuentemente una pasión obsesiva por la dualidad de la psique humana, «lo cual hace posible que el otro yo cuestione cualquier actividad o la sitúe en un marco de referencia más elevado» ${ }^{16}$.

En los cuentos de Cortázar, especialmente los de Bestiario, el doble surge como una interrupción a la personalidad, a la conciencia del personaje. Emerge como aparición esporádica, y llega a consolidarse en definitiva al concluir el relato. Es al principio una interferencia que trae consigo la ruptura al orden establecido. En la mayor parte de los cuentos, el doble es signo de terror y abismo, es angustia provocada por lo siniestro, actúa como un ser extraño, ajeno al yo. Este pretende evadir u ocultar esa identidad ominosa, más no lo consigue: es la identidad reprimida la que termina dominando al sujeto.

Pese a las variaciones que sufre en los diferentes cuentos, mantiene en todos una misma esencia, el doble cortazariano es una identidad presa de la angustia y «nace como una superrealidad de

15 Evelyn Picón Garfield, ¿Es Julio Cortázar un surrealista? (Madrid: Gredos, 1975).

16 Rachel Philips, Las estaciones poéticas en Octavio Paz (México DF: Fondo de Cultura Económica, 1976) 117. 
su poseedor $»^{17}$. Hay en todos una extraña inclinación hacia ese lado ominoso del hombre que busca fusionarse con la realidad externa de su ser. Lo inexplicable y lo oculto se presentan en fuerte pugna con el consciente por exteriorizarse, es una tendencia que busca liberarse irrevocablemente.

$\mathrm{Al}$ respecto García Canclini señala: «Para Cortázar lo bestial es al mismo tiempo algo que él custodia y contra lo cual combate, también algo que lo constituye y lo explica» ${ }^{18}$. Picón añade que tanto en Cortázar como en Breton lo monstruoso tiene dos caras: de un lado la convulsiva que viene a representar el horror siniestro ante el peligro que trasgrede el orden establecido, y de otro el rostro bello, la atracción inexplicable que fascina, en otras palabras, la relación terror/atracción. De tal forma, en el relato cortazariano la noción del doble se complica y se enriquece dejando tanto al personaje como al lector ante «una situación paradójica al borde de un abismo, ante el dilema cósmico del salto, frente a la otredad definitiva. No hay dialéctica sino disociación del ser. El retorno es una condensación ${ }^{19}$.

La transgresión al orden establecido es una forma de revelarse a lo cotidiano, la realidad concreta es transformada por el deseo, por el doble que no es presencia sobrenatural que es a fin de cuentas el yo mismo individual, irreductible, imperecedero, la otredad que ha sido convocada. El cuento «Casa tomada» se desarrolla en una casa antigua, que ha pertenecido por años a una acomodada familia. Al principio del relato, la habita una pareja de hermanos que decidieron, por diferentes razones (rechazo de los pretendientes y muerte de la prometida) permanecer solteros. Fundamentalmente lo siniestro, y en menor medida el doble, se manifiestan de diversas maneras. Los dos hermanos humanizan a la casa, e incluso llegan a considerar que esta es la responsable de que no contrajeran matrimonio: «A veces

17 Gertel Zunilda, «La noche boca arriba, disyunción de la identidad» En: Julio Cortázar. Comp. Pedro Lastra (Madrid: Taurus Ediciones, 1981) 317.

18 Canclini García, Cortázar, una antropología poética (Buenos Aires: Editorial Nova, 1968) 28.

19 Zunilda, 286. 
llegamos a creer que era ella la que no nos dejó casarnos ${ }^{20}$. El varón que narra achaca a la casa sus estados de soledad: hombre y mujer solitarios que viven encerrados en el mundo interior que la casa les construye. En la época en que empieza la narración, los hermanos llevan una tranquila vida que se estructura en torno a la limpieza y mantenimiento de su vivienda. Esta representa para ambos mucho más que un lugar donde vivir: es un sitio seguro y acogedor, similar al vientre materno. «Nos resultaba grato almorzar pensando en la casa profunda y silenciosa $»^{21}$.

Esta relación casa-vientre remite a la observación que hace Braunstein al respecto, que cita a Freud: «...muchos otorgarían la corona de lo Unheimlich a la idea de ser enterrados vivos en estado de catalepsia, pero el psicoanálisis nos ha enseñado que esta terrible fantasía sólo es la transformación de otra que en su origen nada tuvo de espantoso, sino que, por el contrario, se apoyaba en cierta voluptuosidad: la fantasía de vivir en el vientre materno $»^{22}$.

De esta identificación de la casa con el vientre materno podemos discurrir en dos diferentes vías: la primera haría pensar que los «seres» (porque no encontramos otro nombre para designarlos) que toman la casa se vuelven siniestros, porque obligan a abandonar tan acogedor lugar. En este sentido cabe recordar una de las definiciones que da Freud de lo siniestro: «aquella suerte de espantoso que afecta las cosas conocidas y familiares desde tiempo atrás ${ }^{23}$. La otra, lleva a pensar que el deseo 'primigenio' de volver al vientre materno se ha manifestado, lo cual nos conduce nuevamente a Freud: nada puede ser más siniestro que ver la imagen del propio deseo hecha realidad. Por tal razón los habitantes recurren a la fantasía, el ser expulsados a la fuerza por unos misteriosos seres. En esta segunda vía la casa podría representar la materialidad de los lazos afectivos,

20 Cortázar, 9

21 Cortázar, 9.

22 Braunstein, 195.

23 Freud, 2484. 
particularmente los maternos. Cuando se sostiene que «a veces llegamos a creer que era ella la que no nos dejó casarnos» ${ }^{24}$. Conforme a esto, la relación de ambos personajes con la casa adquiere un carácter incestuoso, y por consiguiente, generador de culpa.

Braunstein afirma que sólo hay tumba, confirmación y constancia para quien se ha sometido a los dictados de la ley, de la polis ${ }^{25}$. Ya Freud había dicho que lo siniestro no sería nada realmente nuevo, sino algo que siempre fue familiar a la vida psíquica, y que sólo se tornó extraño mediante el proceso de su represión; algo que debiendo estar oculto, se ha manifestado. Freud afirma que la más habitual de las fantasías es el vivir en el vientre materno. Por otra parte, el ser humano se presenta como un sujeto del deseo inconsciente y por tanto impugnador y transgresor de los órdenes y las órdenes. ${ }^{26}$

La primera prohibición, en torno a la cual se construye la cultura, es la del incesto, una forma corporal de regresar al vientre de la madre. Por esto, el sujeto humano debe vivir en el malestar permanente, ya que la cultura señala prohibiciones, le exige renunciar para siempre al único objeto de placer que sería posible.

Así, que los hermanos se convierten en transgresores de la ley, en tanto que disfrutan el incesto permanente con la casa-madre. Ahora bien, ¿son transgresores, y por tanto culpables, de cometer también incesto entre ellos? Es pregunta arriesgada, de la que no hay pruebas claras; sin embargo, ciertos pasajes del texto podrían dar pie para plantear tal interrogante: «Nos divertíamos mucho, cada uno en sus cosas, casi siempre reunidos en el dormitorio de Irene que era más cómodo $»^{27}$. O cuando se afirma: «Nuestros dormitorios tenían el living de por medio, pero de noche se escuchaba cualquier cosa en la casa. Nos oíamos respirar, toser, presentíamos el ademán que conduce a la llave del velador, los mutuos y frecuentes insomnios ${ }^{28}$.

\footnotetext{
24 Cortázar, 9.

25 Braunstein, 206.

26 Braunstein, 215.

27 Cortázar, 15.

28 Cortázar,16.
} 
En una relación de hermandad total (persiste la presunción del incesto entre ambos), los hermanos viven por y para la casa. Así: «Nos habituamos Irene y yo a persistir solos en ella, lo que era una locura pues en esa casa podían vivir ocho personas sin estorbarse $»^{29}$. Es revelador que el narrador reconozca la locura de ambos de vivir solos en la casa, a pesar de que esta podía albergar, incluso, a ocho personas.

Vale la pena destacar una palabra que utiliza el personaje en la cita anterior: persistir, que recuerda la obstinación, la porfía, a pesar de todo, por continuar en ese lugar. Desde el punto de vista del narrador-personaje, es una obstinación por continuar viviendo una especie de locura. Pese a este estado, la vida cotidiana se torna rutinaria a causa de las atenciones que la vivienda exige, empezando por el hábito o rito de la limpieza, que se ejecuta en los primeros tiempos de siete a once de la mañana, posteriormente almuerzan juntos para disfrutar de una tarde sin obligaciones.

Serán los invasores del hogar, esos «seres» los responsables de la desdicha de los hermanos o ¿será la culpa la que llega a expulsar a este semi-matrimonio? Efectivamente, hasta el final del relato se duda su existencia, si es material real, o producto de la imaginación de los hermanos solitarios. Cabe recordar a Freud, citando a Jetsch, que plantea: «Uno de los procedimientos más seguros para evocar fácilmente lo siniestro mediante las narraciones, consiste en dejar que el lector dude de si determinada figura que se le presenta a una persona es una persona o un autómata. Esto debe hacerse de manera que la incertidumbre no se convierta en el punto central de la atención, porque es preciso que el lector no llegue a examinar y a verificar inmediatamente el asunto $»^{30}$.

La presencia de este efecto se observar en «Casa tomada», pero no con autómatas, sino como otra suerte de visitantes imaginarios, de ánimas. Ni siquiera al final se aclara el carácter de los invasores de la casa: «Antes de alejarnos tuve lástima, cerré bien la puerta de 
entrada y tiré la llave a la alcantarilla. No fuese que a algún pobre diablo se le ocurriera robar y se metiera en la casa, a esa hora y con la casa tomada $»^{31}$.

El animismo, otra de las formas de manifestación de lo siniestro, se caracteriza por la pululación de espíritus humanos en el mundo, por la sobrestimación narcisista de los propios procesos psíquicos, por la omnipotencia del pensamiento y por la técnica de la magia que en ella se basa, por la atribución de fuerzas mágicas minuciosamente graduadas a personas extrañas y a objetos ${ }^{32}$. Por otra parte, la convivencia en la casa familiar se presenta como una reiteración, como una costumbre que proviene desde el tiempo de los bisabuelos. Los dos hermanos se consideran a sí mismos los encargados de romper esta reiteración familiar. «Entramos en los cuarenta años con la inexpresada idea de que el nuestro, simple matrimonio de hermanos, era necesaria clausura de la genealogía asentada por los bisabuelos en nuestra casa ${ }^{33}$.

Para Freud, la reiteración es una de las formas en que se presenta el doble en una narración como el constante retorno a lo semejante, con la repetición de los mismos rasgos faciales, caracteres, destinos, actos criminales, aun de los mismos nombres en varias generaciones sucesivas ${ }^{34}$. Cuando el narrador manifiesta «no sé por qué tejía tanto...» $\gg^{35}$, alude a lo siniestro, como reiteración, como una obsesión inexplicable que obliga a la hermana a tejer y tejer constantemente.

Por su parte, «Carta a una señorita en París» es un cuento narrado en primera persona, mediante una carta. Presenta inicialmente la preocupación del personaje por justificarse ante Andrée, la dueña de un departamento donde está como huésped, por el desastre que ha provocado en el lugar. Acudiendo a fenómenos fantásticos, hechos insólitos tales como vomitar conejitos, Cortázar toma como pretexto

31 Cortázar, 18.

32 Freud, 2497.

33 Cortázar, 10.

34 Freud, 2493.

35 Cortázar, 10. 
esta fábula para trasladarnos a las más recónditas regiones de nuestro propio ser, del ser humano, mostrándonos así un deseo u objeto real interno en fuerte pugna por salir y manifestarse.

El personaje, de quien sabemos que es varón, no obstante que desconocemos su identidad, se introduce en un orden cerrado, un estado de equilibrio representado aquí por el departamento de la supuesta destinataria de sus cartas y ahí se inicia la esquizofrenia: «... (no quería venirme a vivir a su departamento)... más bien porque me duele ingresar en un orden cerrado, construido ya hasta en las más finas mallas del aire...» ${ }^{36}$.

Desde el principio se hace evidente que Andrée tiene obsesión por el orden y que ha dispuesto cada objeto de su departamento de tal forma que mover uno es alterar el otro: «...Mover esa tacita altera el juego de relaciones de toda la casa, de cada objeto con otro, de cada momento de su alma con el alma entera de la casa y su habitante lejana.... $\gg^{37}$. Este mundo aparentemente bello, armonioso, delicado e incluso algo burgués de Andrée contrasta fuertemente con el mundo sombrío, inestable y deprimente del protagonista, que se ve a sí mismo «como perseguido por un universo hostil» ${ }^{38}$. «He cerrado tantas maletas en mi vida, me he pasado tantas horas haciendo equipajes que no llevaban a ninguna parte...cuando yo veo las correas de las valijas es como si viera sombras, elementos de un látigo que me azota indirectamente, de la manera más sutil y más terrible... $\gg^{39}$.

Esta inestabilidad habitual, de no permanecer en lugar fijo, carecer de un hogar (Heim), de pasar la vida haciendo maletas, pese a la angustia que provoca, es un rasgo significativo en la caracterización de este personaje y un factor importante en el acercamiento que pretendemos a Freud y a lo Unheimlich. Sin embargo, el narrador no

\footnotetext{
36 Cortázar, 17.

37 Cortázar, 20.

38 Lanin Gyurko, «La fantasía como emancipación y como tiranía en tres cuentos de Cortázar», Revista Iberoamericana XLI, 91 (1975): 221.

39 Cortázar, 21.
} 
nos permite conocer las causas aparentes que llevaron al personaje a elegir esa vida nómada.

El problemático héroe ha ingresado a un estado de equilibrio, a un orden al cual aparentemente no se quiere someter; a la vez lo encontramos presa del temor a transgredir esas normas, introduciéndose en una profunda angustia que se torna obsesiva en el transcurso del relato, justo lo que Freud denomina con el término Unheimlich.

Surge entonces una tendencia reveladora y liberadora a la vez, el individuo empieza a vomitar conejitos repetidamente, hecho que había vivido ya con anterioridad, esporádicamente. Empero, con la entrada al régimen del apartamento y al tornarse repetitivo, provoca una psicosis obsesiva en el protagonista, situación que nos hace reflexionar sobre la tesis de Freud con respecto a lo siniestro: «... algo que no sería nada nuevo, sino más bien algo que fue familiar a la vida psíquica y que se nos hizo extraño mediante el proceso de represión ${ }^{40}$. Incluso en el caso de la repetición involuntaria, «... que hace parecer siniestro lo que en otras circunstancias sería inocente, imponiéndose así la idea de lo nefasto, lo ineludible, cuando en otro caso se habría hablado de casualidad $»^{41}$.

Interiormente se es portador de un «algo» sin saberlo pero a partir de un cierto momento ha de ser reconocido, se le sabe, «se convierte en algo irreprimible que necesita manifestarse $\gg^{42}$, es un deseo que reside en el inconsciente del mismo actor, no fuera de él y además lo determina al ir tomando forma en su ser. Sin embargo, ese instante que marca la ruptura da inicio a un sufrimiento, a una incomodidad, a -como apunta Jitrik- «una gravidez connotada por la extrañeza ${ }^{43}$, lo cual es Unheimlich, «algo que debiendo haber quedado oculto, secreto, se ha manifestado» ${ }^{44}$.

\footnotetext{
40 Freud, 2495.

41 Freud, 2495.

42 Noel Jitrik y otros, Notas sobre la zona sagrada y el mundo de los otros en Bestiario de Julio Cortázar. (Buenos Aires: Carlos Pérez Editor, 1969) 13.

43 Jitrik, 15.

44 Freud, 2495.
} 
No obstante, esta manifestación no ocurre sin contrapartida. Recordemos con Braunstein que los diques (dikhé) al deseo del hombre son necesarios para que exista el deseo represado, hacedor del hombre como ser cultural; lo cual nos hace considerar la voluntad obsesiva del personaje por ocultar la aparente irracionalidad de vomitar conejitos, a la supuesta racionalidad de los otros. Pensando, como primera instancia en liquidarlos, más eso se hace imposible, sería tan duro como acabar con un hijo propio, entonces: «... usted ha de amar el bello armario de su dormitorio, con la gran puerta que se abre generosa, las tablas vacías a la espera de mi ropa. Ahora los tengo ahí. Ahí dentro. Verdad que parece imposible ${ }^{45}$.

He aquí la ambivalencia del plano en que se mueve este sujeto: los conejitos no son más que un deseo interior, que intenta revelarse a ese orden que le humilla, que no le permite ser él mismo, y ante todo que no le da licencia para expresarse a plenitud. La experiencia de vomitarlos no es considerada como algo repulsivo, mucho menos inmoral o grotesco, es más un acto agradable a su ego, una necesidad irreductible, casi un mecanismo de defensa mediante el cual hace emerger su individualidad reafirmándola. Lo que está contra las normas es su deseo inconsciente, que lo convierte en sujeto Unheimlich, «por cuanto es sujeto del deseo inconsciente, por cuanto impugnador y transgresor de este orden $»^{46}$. No obstante, la contradicción es clara al desear no sólo ocultarlos sino también controlarlos: «... mientras yo quisiera verlos quietos, verlos a mis pies y quietos, un poco el deseo de todo dios, Andrée, el sueño nunca cumplido de los dioses $»^{47}$.

Por tanto, necesita subordinar de alguna manera esa individualidad a un sistema, ya sea al orden de Andrée, o incluso, recordemos, «al mundo mecanizado de su lugar de trabajo donde su

\footnotetext{
45 Cortázar, 25.

46 Braunstein, 215.

47 Cortázar, 27.
} 
comportamiento debe ser moldeado alrededor del orden creado por otro individuo» ${ }^{48}$

La incertidumbre en su carácter rebelde-conformista de compartir y refutar la renuncia a su deseo se hace bastante evidente; de hecho adquiere mayor importancia al analizar su comportamiento cotidiano con respecto a la dicotomía noche-día, o si se quiere sueño-vigilia. Es claro a lo largo del cuento el temor del personaje a enfrentar la noche: «(Sara)... se encierra en su cuarto y de pronto estoy yo solo, sólo con el armario condenado, sólo con mi deber y mi tristeza ${ }^{49}$.

Los conejitos duermen encerrados en el armario durante el día, esto le permite al sujeto llevar una vida socialmente normal, aceptable: «... con la puerta cerrada, el armario es una noche diurna solamente para ellos, allí duermen su noche con sosegada obediencia» ${ }^{50}$. Lo que contribuye a la demostración de que ese deseo es reprimido a los ojos ajenos e incluso a sí mismo durante la vigilia, en sus momentos de conciencia, mientras que al llegar la noche, al enfrentar su soledad, el deseo es el que domina al sujeto. Según el diccionario de símbolos tradicionales de Juan Eduardo Cirlot: «La noche está relacionada con el principio pasivo, lo femenino y el inconsciente. Hesíodo le dio el nombre de madre de los dioses por ser opinión de los griegos que la noche y las tinieblas han precedido la formación de todas las cosas. Por ello, como las aguas tiene un significado de fertilidad, virtualidad, simiente. Como estado previo, no es aún el día, pero lo promete y lo prepara. Tiene el mismo sentido que el color negro y la muerte en la doctrina tradicional $»^{51}$.

Estamos, evidentemente, ante un obseso que teme la llegada de la noche por un gran motivo; si rescatamos de esta definición en primer lugar la relación noche-inconsciencia nos vamos acercando más a Freud, ¿por qué? En general, la noche implica dormir, descansar de

\footnotetext{
48 Gyurko, 221.

49 Cortázar, 27.

50 Cortázar, 30.

51 Juan Eduardo Cirlot, Diccionario de símbolos tradicionales (Barcelona: Luis Miracle, 1958)310.
} 
la vigilia y abrir paso al sueño y este no es más que el despertar del inconsciente. Según el psicoanálisis, los sueños son reveladores de tendencias internas, ocultas parcial o totalmente a nuestra conciencia, mediante la represión es ese encuentro yo con yo que nos define, el desdoblamiento que da paso a un otro yo desconocido. Al respecto señala Braunstein: «Cada vez que nos dormimos arrojamos de nosotros como a una vestidura, esa eticidad nuestra que hemos adquirido con tanto trabajo... para volvérnosla a poner cada mañana $»^{52}$.

Rescatemos también de ese binomio negro (noche) y muerte en la doctrina tradicional que la obscuridad nos provoca miedo, angustia, soledad, porque es lo más semejante a la muerte. Sin embargo, sobre esto afirma Braunstein que el deseo es Unheimlich «... porque no tiene en cuenta a la muerte, y de ese modo arranca y devuelve a lo familiar, al nido, al claustro ${ }^{53}$.

¿No podemos acaso deducir que este desgraciado individuo ha tenido que enfrentarse irrevocablemente a su imposible objeto del deseo, al cual supuestamente había renunciado? Retomemos las tesis de Freud citadas por Braunstein en las cuales revela que «nada es más pavoroso, más siniestro, que ver la imagen del propio deseo hecha realidad $»^{54}$. Esa tendencia del sujeto no es socialmente aceptada; por tanto, tiende a ocultarla o evadirla, no obstante está ahí presente, «imperecedero e insaciable desde el freno que se le pretende imponer $»^{55}$, y que se consolida en la alucinación de esas siniestras noches repetidamente, de esa otra escena del sueño y: «... la representación de esta realización no distorsionada del deseo en la alucinación onírica pone al hombre normal más o menos neurótico, en contacto con lo inconciliable, lo inaceptable. Allí fracasa la función del sueño de proteger el dormir y el sujeto, confrontado con la revelación de ese real irreductible de su deseo, despierta presa de

\footnotetext{
52 Braunstein, 213.

53 Braunstein, 213.

54 Braunstein, 214.

55 Braunstein, 207.
} 
la angustia, de una angustia que solo puede recibir el calificativo de mortal. Pues la realización del deseo saca al hombre de su morada, donde recibe su identidad. Es lo Unheimlich por excelencia ${ }^{56}$.

Con base en ello, podría ser el enfrentamiento con el deseo lo que impulsa al personaje a elegir la muerte como salida, porque el «in crescendo» de su deseo (ya no son diez conejitos sino once, feos y con el pelo largo, ya adolescentes), ahora no solamente es incontrolable, sino que han controlado al sujeto completamente, «estuvieron en círculo bajo la luz de la lámpara, en círculo y como adorándome y de pronto gritaban, gritaban como yo no creo que griten los conejos» ${ }^{57}$.

Este ritual hace evidente y solo puede indicarnos un hecho: sus impulsos internos por fin han triunfado sobre su conciencia, la renuncia al objeto del deseo ha quedado truncada y, ante el horror que le provoca, su única salida es la muerte. La carta escrita y nunca enviada a Andrée (quien probablemente no exista como tal sino más bien como su conciencia represora), se convierte en una nota de suicidio, constituye una última tentativa de autojustificación: «no me lo reproche Andrée, no me lo reproche $»^{58}$.

En el caso de «Lejana» se presenta como el doble. A grandes rasgos el relato trata de una mujer a punto de contraer matrimonio y que siempre mantiene una comunicación interior con otra mujer, la cual lleva a cabo actividades que la mujer Alina Reyes, siente en carne propia: «Puedo solamente odiarla tanto, aborrecer las manos que la tiran al suelo y también a ella, a ella todavía más porque le pegan, porque soy yo y le pegan $»^{59}$.

Este odio es hacia la lejana pero también es un odio hacia ella misma, ya que existe una fusión total entre los dos seres. Esta comunicación interior y a distancia es un tipo de telepatía, ya que existe

\footnotetext{
56 Braunstein, 207.

57 Cortázar, 32.

58 Cortázar, 21.

59 Cortázar, 37.
} 
un diálogo que permite el contacto entre ambas. Freud menciona que otro de los aspectos que provoca el efecto de lo siniestro es el tema del doble, del otro yo, con sus múltiples variaciones: «La aparición de personas que a causa de su figura igual deben ser consideradas idénticas; el acrecentamiento de esta relación mediante la transmisión de los procesos anímicos de una persona a su doble (telepatía), de modo que uno participa en lo que el otro sabe, siente, piensa y experimenta; la identificación de una persona con otra, de manera que se pierde el dominio sobre su propio yo, es decir desdoblamiento del yo, partición del yo, sustitución del yo; y el constante retorno a lo semejante, con la repetición de los mismos rasgos faciales, caracteres, destinos, actos criminales, aún de los mismos nombres en varias generaciones sucesivas ${ }^{60}$.

El doble se trata estéticamente de una manera sutil y al mismo tiempo directa, dejando entrever una dualidad, una personalidad dividida. La Lejana, nombre que le viene bien a la mujer ausente ya que se encuentra lejos, a distancia de la mujer 1, es maltratada y sufre horrores por la pobreza en que vive y Cortázar lo expone muy bien con sólo mencionar su nombre, la mendiga de Budapest.

El inminente matrimonio de Alina Reyes es el elemento legitimador que hace posible la unión, el encuentro entre los dos seres. En este relato existe una extraña asechanza. Malva Filer afirma que: «en el mundo de Cortázar no hay garantías para la preservación del yo, así como tampoco la hay para el pacífico goce de la rutina» ${ }^{61}$.

La construcción fantástica cortazariana supone una lectura de sentido diferente a la tradicional y que, a partir, de una particular imagen se articula en bloques que se copertenecen. Esta lectura no es alegórica, si se entiende por ello el desciframiento de claves. Todo lo contrario: hay que entenderlas como proposiciones reales. Es de la esencia de lo fantástico que no quepa esa transformación: hay que

60 Freud, 2493.

61 Malva Filer, «Las transformaciones del yo en la obrade JulioCortázar», Cuadernos Hispanoamericanos (Madrid, 1970). 648. 
dar por supuesta la existencia del terror, de lo ominoso, de la muerte con un trasfondo de sí misma, de la asechanza. Pero también, y junto con ello, de una actitud del narrador que borra las fronteras de lo real y fantástico, que deshace los límites y que propicia una colusión, un entrar suave, misterioso, paradójico, ambas existencias hasta permitir su transformación total: la de la nueva existencia.

Muchos puntos podrían retomarse en este análisis; por ejemplo, el que ese doble de Alina Reyes es su secreto, algo que mantiene oculto, que no lo comunica ni a su madre ni a su hermana, ni a ninguna otra persona, esto ligado al hecho de que el texto sea escrito en forma de diario, lo cual viene a suponer un grado de secreto y privacidad. La Lejana no aparece en el texto con nombre propio, lo cual le da al lector la libertad para imaginar que esta lejana mujer podría ser cualquier persona que se encuentra a distancia, podría ser cualquier mujer que se encuentra en condiciones deplorables, que sufre y pasa frío.

En este cuento, el doble aparece como algo ominoso o siniestro, pero a la vez como un encuentro, una fusión del yo reconfortante y reivindicadora: «En el puente la hallaré y nos miraremos. [...] Y será la victoria de la reina sobre esa adherencia maligna, esa usurpación indebida y sorda. Se doblegará si realmente soy yo, se sumará a mi zona iluminada, más bella y cierta; con sólo ir a su lado y apoyarle una mano en el hombro» ${ }^{62}$. Este encuentro de los dos yo, se realiza en un puente, hecho muy significativo, ya que el puente es un símbolo de unión y desunión, un instrumento que lleva a encontrar dos orillas de tierra, en este caso la fusión del doble, el encuentro de Alina con la mendiga de Budapest: «Sin temor, liberándose al fin -lo creía con un salto terrible de júbilo y frío- estuvo junto a ella y alargó también las manos, negándose a pensar, y la mujer del puente se apretó contra su pecho y las dos se abrazaron rígidas y calladas en el puente, con el río trizado golpeando en los pilares» ${ }^{63}$.

62 Cortázar, 47.

63 Cortázar, 48. 
Existen diferentes pistas en el texto, ya citadas, que no dejan duda de que existe un doble de Alina Reyes, un doble que sufre y que al final del relato se fusiona totalmente con ella. No obstante, salta la duda y al mismo tiempo si todo esto que se describe en el cuento fue sólo un sueño de Alina y nunca ocurrió, pregunta que sería bastante difícil de responder, aunque la duda y la interrogante deja abierta la posibilidad de muchos otros análisis. Y anotaremos a continuación fragmentos textuales, los cuales crean la incertidumbre y ayudan a la emergencia de esta pregunta: «Sólo queda Budapest porque allí es el frío, allí me pegan y me ultrajan. Allí (lo he soñado, no es más que un sueño, pero como se adhiere y se insinúa hacia la vigilia) $\gg^{64}$. Y: «Al abrir los ojos (tal vez gritaba ya) vio que se habían separado $»^{65}$.

No se puede afirmar que no haya sido un sueño, o que tal vez sí lo era. Sin embargo, es lo fantástico de la literatura: permite que la mente del lector cree alternativas de respuesta y sobre todo trascienda los límites de lo racional y aberrado de la realidad. 